www.jmscr.igmpublication.org

Impact Factor 5.84

Index Copernicus Value: 83.27

ISSN (e)-2347-176x ISSN (p) 2455-0450

crossref DOI:_https://dx.doi.org/10.18535/jmscr/v5i4.16

Journal Of Medical Science And Clinical Research

\title{
Functional Outcome after Surgical Stabilization of Fractures of Distal End of Radius with or Without Ulnar Styloid Fractures- A Comparative Study
}

Authors

\section{Dr R. Srikanth Varma1, Dr Srikanth Gowrala ${ }^{2}$, Dr Saikiran Balagondi ${ }^{3}$}

${ }^{1}$ Associate Professor Kamineni Academy of Medical Sciences Research Centre Hyderabad

${ }^{2}$ Registrar Kamineni Institute of Medical Sciences, Narketpally

${ }^{3}$ Assistant Professor Kamineni Academy of Medical Sciences and Research Center, Hyderabad Email-dr_srikanthvarma@yahoo.co.in,shrikanthgowrala05@gmail.com,saikiranbalagondi@gmail.com

\begin{abstract}
Background: The impact of an unrepaired fracture of the ulnar styloid process on recovery after internal fixation of a fracture of the distal part of the radius is uncertain. We evaluated a series of patients with an internally stabilised fracture of the distal part of the radius to test whether there is any difference in wrist motion or function scores between those with an untreated fracture of the ulnar styloid process and those with no ulnar fracture.

Materials \& Methods: The present study was a prospective comparative study conducted between April 2015 to November 2015. Total 60 patients have been operated with open reduction and internal fixation with plating. 52 patients who fulfilled the inclusion criteria were taken up for study and grouped into two groups at 1:1 ratio. The average follow up period was 6 months. Patients were followed up in the outpatient department on 10th post operative day for suture removal, and further at 4 weeks, 8 weeks, 12 weeks, 16 weeks, 20 weeks, 12 months postoperatively and were analysed with wrist ROM, DASH score, Gartland and Werley system and visual analogue score.

Results: In the present study 52 cases are included, GROUP A-26, GROUP B-26, GROUP A: distal radius fractures without ulnar styloid fracture, GROUP B: distal radius fractures with ulnar styloid fracture. The two groups were comparable with regard to age, gender, side of the fracture, type of the fracture and nature of injury.

All patients were operated under general anaesthesia. We found out that the variables compared between patients with ulnar styloid fractures and without ulnar styloid fractures like Wrist range of movements, DASH Score, Gartland and Werley System score and visual analogue scale differences were statistically insignificant. One patient had a superficial infection which subsided with antibiotic therapy and three patients had malunion which did not affect the final functional outcome.

Conclusion: An unrepaired fracture of the ulnar styloid process does not appear to influence functional outcome after treatment of a distal radial fracture with plate-and-screw fixation.
\end{abstract}

\section{Introduction}

Distal radius fractures represent approximately one-sixth of all fractures treated in emergency departments ${ }^{1}$. Whenever a person falls, hand comes for protection instinctively there by putting the wrist joint more prone for injury. Fractures of 
the distal part of the radius are commonly associated with a fracture of the ulnar styloidprocess. Frykman, in his classic article, reported that ulnar styloid fractures occurred in approximately $61 \%$ of distal radius fractures ${ }^{2}$. Though the incidence of associated ulnar styloid fracture is high, not much significance is given to this fracture and at times it may be under treated. Associated Injuries to triangular fibro cartilage complex can cause symptoms like pain and instability when untreated but there are no clear reports of influence of ulnar styloid fractures on final outcome of surgically treated distal radius fractures. There are no clear reports to clarify the debate between those who believe that associated ulnar styloid fractures can cause arthritis, chronic instability and pain in the wrist joint ${ }^{3-6}$ and those who do not ${ }^{7,8}$.

Hence in this study we are comparing the functional outcome after surgical fixation of fractures of the distal part of the radius, matched cohorts of patients with and without an untreated fracture of the distal ulna to test the importance of ulnar styloid fracture.

\section{Material and Methods}

This is a prospective comparative study. Between April 2015 and November 2015, 52 patients with closed fracture of distal end of radius which can be treated with open reduction and internal fixation were included in the study. All the patients are within the age group of 19 years to 65 years, and there are 33 males and 19 females. Patients were divided in to two groups with equal number (26) of patients in each group. In group A, patients had distal radius fracture with associated ulnar styloid fracture and in group B, there was no associated ulnar styloid fracture. Patients with open fractures requiring soft tissue reconstruction, co-existing fractures of the radius and ulna proximally, pathological fractures, patients with morbid illness, associated neurovascular injuries, co existing carpal bone fractures were not included in the study.
Patients were subjected to thorough clinical examination and radiological examination with $\mathrm{x}$ rays in two views (antero posterior and lateral views) and classified as per Frykman ${ }^{9}$ (1967) classification that incorporated individual involvement of the radio carpal and radioulnar joints and involvement of ulnar styloid. Since our study involves ulnar styloid we have used this classification for our study.

The distal radius fractures were treated with open reduction and internal fixation with plating. Immediate post operative check $\mathrm{X}$-rays were taken in both AP and lateral views. Active exercises of all the fingers, elbow and shoulder were carried out. Sutures were removed on the 10th post operative day.

Results were assessed with

1. Wrist Range of motion using Goniometer

2. DASH(Disability of arm, shoulder and hand) score

3. Gartland and Werley system of scoring(Demerit point rating system) ${ }^{17}$

4. Visual analogue score.

Patients were followed up in the outpatient department on 10th post operative day for suture removal, and further at 4 weeks, 8 weeks, 12 weeks, 16 weeks, 20 weeks, 12 months for the above assessment tools.

\section{Data Analysis}

The data was reported as the mean $+\mathrm{SD}$. The differences in quantitative variables between groups were assessed by means of the Independent sample student T-test. The chi square test was used to assess differences in categorical variables between groups. A " $p$ " value of $<0.05$ using a two-tailed test was taken as being of significance for all statistical tests. All data were analyzed with a statistical software package. (SPSS, version 19.0 for windows).

\section{Results}

Outcome was studied with following parameters:

1. Range of motion at the wrist

2. Pain-visual analogue scale 
3. Functional outcome with DASH score

4. Gartland and Werley system score.

Range of Motion at the Wrist between The Two Groups

\begin{tabular}{|l|c|c|c|}
\hline Range of motion & GROUP A & GROUP B & P-value \\
\hline Palmar flexion & 51.615 & 50.5 & 0.269 \\
\hline Dorsiflexion & 59.269 & 58.384 & 0.542 \\
\hline Supination & 79.769 & 78.538 & 0.096 \\
\hline Pronation & 81 & 80.384 & 0.341 \\
\hline Radial deviation & 18.961 & 18.80 & 0.706 \\
\hline Ulnar deviation & 30.153 & 29.307 & 0.351 \\
\hline
\end{tabular}

\section{Visual Analogue Scale}

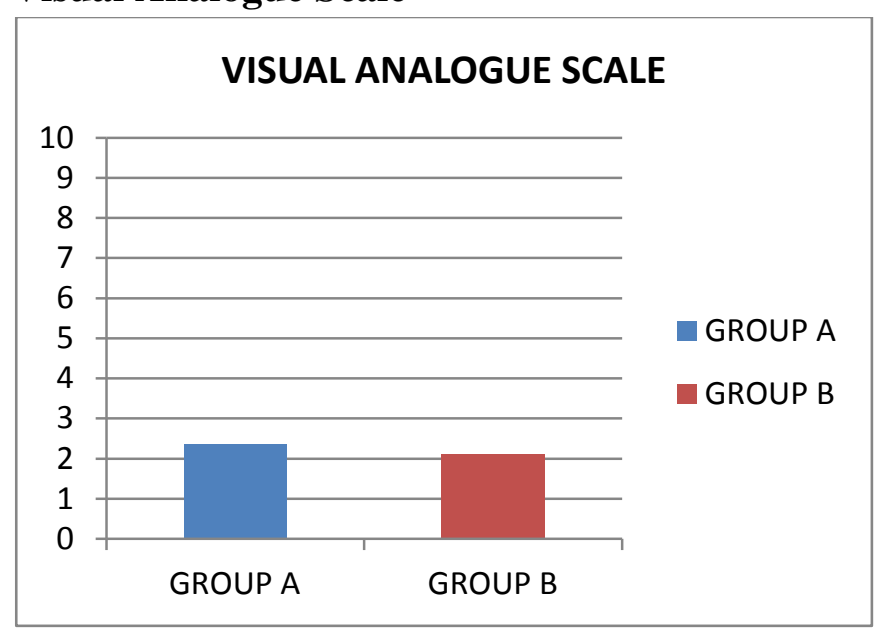

Graph 10: Visual Analogue Scale

The $\mathrm{p}$ value is 0.276 , hence the visual analogue scale is comparable between the two groups, and hence they are not statistically significant.

\section{Disability of Arm Shoulder and Hand (Dash) Score}

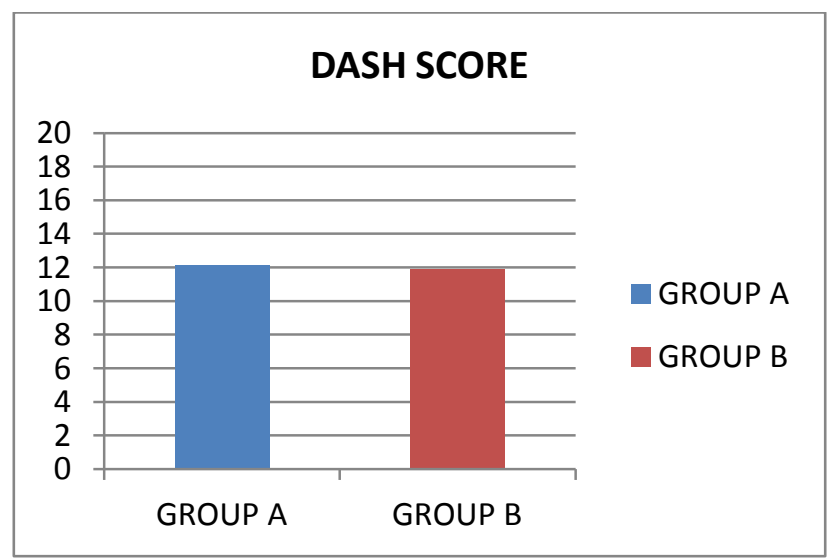

Graph 11: Disability of Arm Shoulder and Hand (Dash) Score

The $\mathrm{p}$ value is 0.333 , hence the DASH score is comparable between the two groups, hence they are not statistically significant.
Gartland and Werley System Score

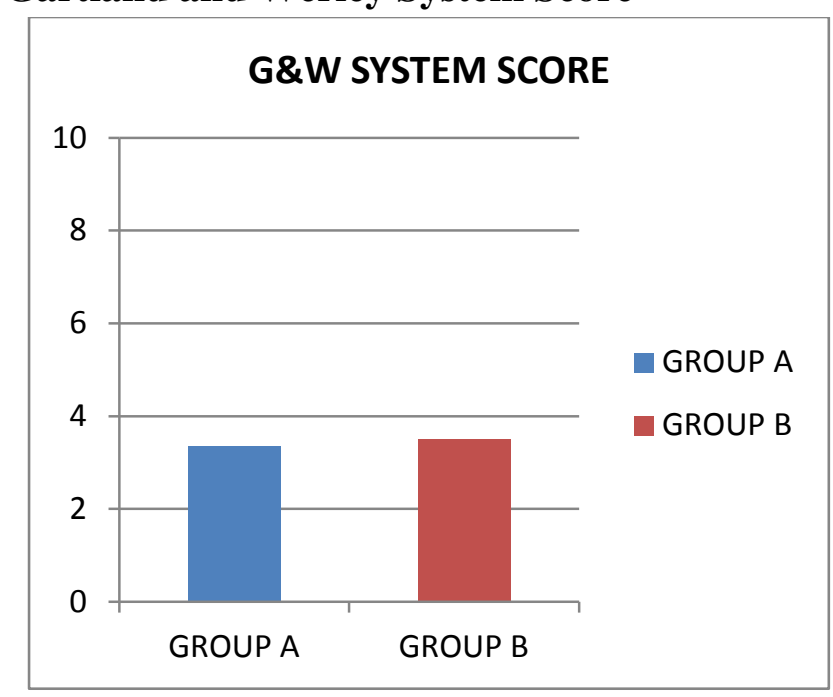

Graph 12: Gartland and Werley System Score

The $\mathrm{p}$ value is 0.747 , hence the Gartland and Werley system score is comparable between the two groups, hence they are not statistically significant.

There was one case of superficial infection which was subsided with antibiotics and serial dressings and 3 cases of malunion were seen with no major functional disturbance.

\section{Discussion}

In our study good results were seen in both the groups either with ulnar styloid fracture or without ulnar styloid fracture.

The ulnar styloid is a continuation of the subcutaneous ridge of the ulna, projecting 2 to 6 $\mathrm{mm}$ distally. It provides an increased area for soft tissue attachments, including the extensor carpi ulnaris (ECU) tendon sheath and the secondary attachments of the radioulnar ligaments.

Palmar and dorsal radioulnar ligaments, which are parts of the TFCC, extend from the sigmoid notch of the radius to converge in a triangular configuration to attach to the ulna. They divide in coronal plane into deep or proximal limb, to get attached to fovea and the superficial or distal limb to attach to the base and mid portion of the ulnar styloid. The space between the limbs near the ulnar styloid contains richly vascularised loose connective tissue. This tissue is sometimes called the ligamentumsubcruetum. The diverging fibre 
arrangement of the radioulnar ligaments has important clinical implications, especially in relation to ulnar styloid fractures. A basilar styloid fracture imparts mechanical discontinuity to the superficial limbs and signifies potential disruption of the deep limbs because of its proximity to their foveal attachments ${ }^{10}$. So based on these anatomical findings, a fracture of ulnar styloid process per se may have some influence on overall outcome apart from the influence of its TFCC injury leading to DRUJ instability.

There are clear indications for the treatment of ulnar styloid fractures when there is instability of distal radioulnar joint after accurate reduction of distal radius fracture ${ }^{10}$. But there are no reports on influence of untreated ulnar styloid fractures without DRUJ instability on immediate or long term functional outcome of distal radius fractures treated with plating.

Several authors have identified that fracture base of ulnar styloid process as a potential cause of inferior outcome in patients with distal end radius fractures ${ }^{11,12,13,14}$.

May et.,al ${ }^{11}$ studied 166 patients with distal radial fracture and found 14 of them with DRUJ instability. 11 patients among these 14 were found to have ulnar styloid base fracture. They concluded that ulnar styloid fracture with displacement more than $2 \mathrm{~mm}$ is risk factor for DRUJ instability.

Souer et.,al ${ }^{15}$ in a matched cohort study of patients with or without ulnar styloid base fracture (76 in each group) having distal radius volar plating and followed up for 24 months, found no measurable differences in motion, strength, pain, or functional scores based on presence of styloid fracture or on initial displacement of more or less than $2 \mathrm{~mm}$. The authors did not specifically assess DRUJ instability before or after surgery.

Zenke et $\mathrm{al}^{16}$ reported a case series of 118 distal radius fractures treated with volar plating, 68 with and 50 without ulnar styloid fractures. The authors found higher rates of ulnar-sided wrist pain in those with increased initial ulnar variance but no differences in ulnar-sided wrist pain, range of motion, or grip strength based on presence, size, or displacement of a styloid fracture.

We have evaluated the patients with tools for functional outcome only. Patients with DRUJ instability were excluded from the study to maintain the uniformity of sample and there by specifically looking for the effect of untreated ulnar styloid fractures on over all functional outcome.

All the parameters that were compared between the two groups had a $\mathrm{p}$ value of more than 0.05 ; hence there was no significant difference in the functional outcome between the two groups.

Hence in our study of patients in whom an unstable fracture of the distal part of the radius had been treated with open reduction and internal fixation, we were unable to demonstrate any differences between the outcomes for the patients who had an untreated fracture of the ulnar styloid process and those patients with no ulnar fracture.

\section{Conclusion}

As per our study good to excellent results were found in almost all the patients with ulnar styloid fracture and without ulnar styloid fracture based on the DASH score, wrist range of motion, Gartland and Werley score and Visual Analog scale.

Since there is no significant difference in the functional outcome of the wrist in patients with ulnar styloid fractures and without ulnar styloid fractures, we conclude that, there is no significant effect of the fracture of the ulnar styloid on the overall functional outcome after surgical fixation of the distal radius and we need not fix the ulnar styloid fractures after surgical stabilization of the distal radius.

\section{References}

1. Bucholz RW, Heckman JD,Court-Brown CM,Rockwood and Green's Fractures in Adults,6th ed. Baltimore, MD:Lippincott USA Williams \&Wilkins;2006.

2. Fyrkman G: Fracture of the distal radius including sequelae-shoulder-hand-finger 
syndrome, disturbance in the distal radioulnar joint and impairment of nerve function. A clinical and experimental study, ActaOrthopScand: Suppl 108:3, 1967.

3. Geissler WB, Fernandez DL, Lamey DM. Distal radioulnar joint injuries associated with fractures of the distal radius. ClinOrthopRelat Res. 1996; 327:135-46.

4. Faierman E, Jupiter JB. The management of acute fractures involving the distal radioulnar joint and distal ulna. Hand Clin. 1998; 14:213-29.

5. Stoffelen D, De Smet L, Broos P. The importance of the distal radioulnar joint in distal radial fractures. J Hand Surg [Br]. 1998;23:507-11

6. Lindau T, Hagberg L, Adlercreutz C, Jonsson K, Aspenberg P. Distal radioulnar instability is an independent worsening factor in distal radial fractures. Clin Orthop Relat Res. 2000;376:229-35.

7. Lindau T, Adlercreutz C, Aspenberg P. Peripheral tears of the triangular fibrocartilage complex cause distal radioulnar joint instability after distal radial fractures. J Hand Surg [Am]. 2000;25:464-8.

8. Lindau $\mathrm{T}$. Treatment of injuries to the ulnar side of the wrist occurring with distal radial fractures. Hand Clin. 2005;21:41725.

9. Frykman G. Fracture of distal Radius, a clinical and experimental study. ActaOrthopScand 1967; 108:143-53.

10. Scott W. Wolfe, Robert N. Hotchkiss , William C. Pederson, Scott H. Kozin, Green's operative Hand Surgery, $6^{\text {th }}$ edition.

11. May MM, Lawton JN, Blazar PE. Ulnar styloid fractures associated with distal radius fractures: incidence and implications for distal radioulnar joint instability. J Hand Surg [Am]. 2002;27:965-71.
12. Geissler WB, Fernandez DL, Lamey DM. Distal radioulnar joint injuries associated with fractures of the distal radius. ClinOrthopRelat Res. 1996; 327:135-46.

13. Stoffelen D, De Smet L, Broos P. The importance of the distal radioulnar joint in distal radial fractures. J Hand Surg [Br]. 1998;23:507-11.

14. Ruch DS, Lumsden BC, Papadonikolakis A. Distal radius fractures: a comparison of tension band wiring versus ulnar outrigger external fixation for the management of distal radioulnar instability. J Hand Surg [Am]. 2005;30:969-77.

15. Souer JS, Ring D, Matschke S, Audige L, Marent-Huber M, Jupiter JB. Effect of an unrepaired fracture of the ulnar styloid base on outcome after plate-and-screw fixation of a distal radial fracture. J Bone Joint Surg 2009;91A:830 - 838.

16. Zenke Y, Sakai A, Oshige T, Moritani S, Nakamura T. The effect of an associated ulnar styloid fracture on the outcome after fixation of a fracture of the distal radius. $\mathrm{J}$ Bone Joint Surg 2009;91B:102-107.

17. Gartland J J, Werley C W, Evaluation of healed Colles fractures. J Bone joint Surg 1951; 33A:859-907. 